\title{
Benign Vokal Kord Patolojilerinde Tedavi Etkinliğinin Ses Analizi ile Değerlendirilmesi
}

\section{Treatment Effectiveness in Benign Vocal Cord Pathologies Evaluation by Sound Analysis}

\author{
Burak Ülkümen $^{1 *}$, Görkem Eskiizmir ${ }^{1}$, Onur Çelik $^{1}$, Onur Dombayc1 ${ }^{1}$ \\ ${ }^{1}$ Manisa Celal Bayar Üniversitesi Kulak Burun ve Boğaz Hastalıkları Anabilim Dalı, Manisa, Türkiye \\ e-mail: drburak@gmail.com, geskiizmir@hotmail.com, onurcelik@yahoo.com, onur.dombayci@gmail.com
}

Orcid: 0000-0003-1981-5886

Orcid: 0000-0002-3125-8288

Orcid: 0000-0001-9188-3467

Orcid: 0000-0003-1236-9908

*Sorumlu Yazar / Corresponding Author: Sorumlu Yazar: Burak Ülkümen ${ }^{1}$

Gönderim Tarihi / Received: 27.05.2020

Kabul Tarihi / Accepted: 18.09.2020

DOI: $10.34087 /$ cbusbed.743655

Giriş ve Amaç: Benign vokal kord patolojilerinde ses terapisi ve fonocerrahinin etkinliğini belirlemek.

Gereç ve Yöntemler: Manisa Celal Bayar Üniversitesi KBB polikliniğine Eylül 2015-Mayıs 2019 tarihleri arasında ses kısıklığı ile başvuran ve akustik ses analizi yapılan $79(35 \mathrm{~K}, 44 \mathrm{E})$ hasta çalışmaya dahil edilmiştir. Ses analizinde hastanın başvuru sırasında ve tedavi sonrası 3. ayda auidio-technica AT2005USB marka mikrofon ile alınan kayıtları karşılaştııılmışıı. Akustik analiz çok boyutlu ses analiz programı (Multi-Dimensional Voice Program- MDVP) kullanılarak yapılmıştır. F0, vF0, Jitter, Shimmer, APQ, NHR ve VTI parametreleri analiz edilmiş̧ir. Ses kayıtları alınmıştır. Ses analizi değerleri gurup bazında tedavi öncesi ve sonrası "eşli örneklem $t$ testi" kullanılarak karşılaştırılmıştır. Veriler ortalama \pm standart sapma (SD) olarak sunulmuştur. Güven aralığı 95\% ve p $<0,05$ olarak istatiksel anlamlı kabul edildi (IBM SPSS Statistics for Windows, Version 21.0.; Armonk, NY, IBM Corp.).

Bulgular: Çalışmamıza dahil olan hastalar dikkate alındığında ses cerrahi öncesi ve sonrası VTI $(p=0.46)$ hariç tüm parametrelerde ( $\mathrm{F} 0, \mathrm{vF} 0$, Jitter, Shimmer, APQ ve NHR) $(\mathrm{p}<0.05)$ istatiksel olarak önemli derecede düzelme tespit edilmiştir. Fonksiyonel disfonilerde ise ses terapisi öncesi ve sonrası karşılaştırıldı ğında vF0, Jitter, Shimmer ve NHR parametrelerinde istatiksel olarak anlamlı düzelme $(\mathrm{p}<0.05)$ tespit edilirken F0 ( $\mathrm{p}=0.09)$, APQ ( $\mathrm{p}=0.06)$ ve VTI $(\mathrm{p}=0.13)$ parametrelerinde istatiksel olarak anlamlı fark bulunmamıştır.

Sonuç: Çalışmamız verileri dikkate alındığında ses terapisinin temel parametrelerde fonocerrahiye yakın etkinlik sağladığı ancak bazı minör parametrelerde yetersiz kaldığı tespit edilmiştir.

Anahtar Kelimeler: Benign, disfoni, fonocerrahi, ses analizi, ses terapisi, vokal kord

\footnotetext{
Abstract

Objective: To determine the efficacy of voice therapy and phono-surgery in benign vocal cord pathologies.

Materials and Methods: 79 (35 K, 44 E) patients who were admitted to the ENT clinic of Manisa Celal Bayar University between September 2015 and May 2019 with hoarseness and who underwent voice analysis were included in the study. Auidio-technica AT2005USB microphone was utilized for comparison of voice at the time of admission and at the 3rd month after treatment. Acoustic analysis was done using a multi-dimensional sound analysis program (MDVP). F0, vF0, Jitter, Shimmer, APQ, NHR and VTI parameters were analyzed. Voice parameters were compared on a group basis before and after treatment by using "paired sample $t$ test". Data are presented as mean \pm standard deviation (SD). The confidence interval was considered statistically significant at $95 \%$ and $\mathrm{p}<0.05$ (IBM SPSS Statistics for Windows, Version 21.0.; Armonk, NY, IBM Corp.).
} 
Results: In benign vocal cord pathologies, comparison of voice parameters before and after the surgery revealed statistically significant improvement in terms of all parameters (F0, vF0, Jitter, Shimmer, APQ and NHR) $(\mathrm{p}<0.05)$ except VTI $(\mathrm{p}=0.46)$. Concerning functional dysphonia, comparison of voice parameters before and after voice therapy revealed statistically significant improvement $(\mathrm{p}<0.05)$ in vF0, Jitter, Shimmer and NHR parameters, but no statistically significant difference in F0 $(p=0.09)$, APQ $(p=0.06)$ and VTI $(p=0.13)$ parameters.

Conclusion: Consequently, it was revealed that voice therapy is efficient as much as the phono-surgery concerning the basic parameters of voice, but not the minor ones.

Keywords: Benign dysphonia, phonosurgery, vocal cord, voice therapy, voice analyses

\section{Giriş}

Benign vokal kord patolojilerinin (BVKP) bir kısmı fonocerrahi (FC) gerektiren vokal kord lezyonları olup bir kısmı da ses terapisi (ST) ile tedavi edilebilen fonksiyonel disfonilerdir (neoplastik olmayan vokal kord patolojileri) [1]. Benign vokal kord lezyonları adından da anlaşılacağ1 üzere vokal kordda ortaya çıkan malign olmayan tüm organik oluşumları içermektedir. Bunlar arasında sık görülenler şarkıcı nodülü, polipler, papillom, polipoid dejenerasyon (Reinke ödemi) ve kistlerdir. Görece daha nadir görülenler ise sulkus vokalis, intrakordal kist, mukozal köprü, kordal varisler ve anterior web olarak sayılabilir.

Vokal kord histolojisi dikkate alındığında epitel ve lamina propria'nın orta katmanı arasında kalan yüzeyel lamina propria katmanı Reinke Boşluğu olarak tanımlanmıştır. Reinke boşluğu aynı zamanda vibratuar (titreşen) katman olarak ta bilinir [2]. Bu katmanda ortaya çıkan benign vokal kord lezyonları esnekliği bozarak addükte vokal kordlarda fonasyon sırasında ortaya çıkan pasif glottal mukozal dalgayı baskılar ya da ortadan kaldırır. Bu nedenle lamina proprianın yüzeyel ve orta katmanında benign vokal kord lezyonları bulunan hastalarda ses kısıklığı, artmış vokal efor, yorgunluk, gerginlik ve eğer lezyonlar yeterince büyükse dispne şikayetleri görülür [3].

ST hem organik hem de fonksiyonel ses hastalıklarında uygulanabilirken FC siklikla sadece organik ses hastalıklarında kullanılmaktadır [4]. Bunun istisnalarından biri cinsiyet değiştiren bireylerde uygulanan FCdir ki bu bireylerde organik bir ses hastalığ olmamasına karşın FC uygulanmaktadır [5]. Disfoni tedavisinde, bireysel medikal endikasyona bağlı olarak FC ve ST'nin her ikisi de objektif ve sübjektif olarak tatminkar sonuçlar elde edilmesini sağlamaktadır [6]. Aslında ST, FC uygulanan hastaların büyük kısmında ikincil veya tamamlayıcı tedavi olarak ta önerilmektedir. Diğer taraftan organik ses bozukluklarında birincil tedavi olarak ta uygulanabilmektedir. Ancak literatür dikkate alındığında organik ses bozukluklarının tedavisinde ses terapisinin birincil kullanımının etkinliği konusunda fikir birliği oluşmamıştır [7].

FC siklıkla neoplastik ya da organik disfoni nedeniyle uygulanır. Söz konusu lezyon mikroflep tekniği ile vokal korddan uzaklaştırıldığında ses parametrelerinde dramatik değişiklik olması beklenmektedir. Oysa fonksiyonel disfonilerde ST uygulandığında kisa dönemde vokal kord histolojisinde ciddi bir değişiklik olması beklenmez. Dolayısıyla ses parametrelerinin en azından FC'de olduğu kadar değişmeyeceği öngörülebilir. $\mathrm{Bu}$ çalışmada kliniğimizde $\mathrm{FC}$ ve ST uygulanan organik ve fonksiyonel benign ses hastalıklarında tedavi öncesi ve sonrası ses değişimini akustik parametreler açısından karşılaştırdık. Bu sayede her iki tedavi yönteminin etkinliğini ortaya koymayı amaçladık.

\section{Materyal ve Metot:}

Retrospektif olarak tasarlanan çalışmamız Manisa Celal Bayar Üniversitesi KBB polikliniğine Eylül 2015-Mayıs 2019 tarihleri arasında ses kısıklığı ile başvuran ve akustik ses analizi yapılan 79 (35 K, 44 E) hasta dahil edilerek yapılmıştır. Malign ve premalign vokal kord patolojisi olan hastalar çalışma dışı bırakılmıştır. Fonocerrahi uygulanan olgular dikkate alındığında nodül, intrakordal kist hastalarında mikroflep tekniği ile mümkün olan en fazla miktarda mukoza korunmasına özen gösterilmiştir. Vokal kord polip hastalarında ise doğrudan eksiyon tercih edilmiştir. Sulkus vokalis olgularında ise elevasyon sonrası temporalis fasyası kullanılmıştır. Ses analizinde hastanın başvuru sırasında alınan kaydı ve tedavi sonrası 3. ay kayıtları karşılaştırılmıştır. Akustik analiz çok boyutlu ses analiz programı (Multi-Dimensional Voice Program- MDVP) kullanılarak yapılmıştır. F0, vF0, Jitter, Shimmer, APQ, NHR ve VTI parametreleri analiz edilmiştir. Ses kayıtları sessiz odada auidio-technica AT2005USB marka mikrofon ile alınmıştır.

Veri dağılımı Shapiro-Wilk testi ile değerlendirilmiştir. Ses analizi değerleri gurup bazında tedavi öncesi ve sonrası "eşli örneklem t testi" kullanılarak karşılaştırılmıştır. Veriler ortalama \pm standart sapma (SD) olarak sunulmuştur. Güven aralığ $195 \%$ ve $p<0.05$ olarak istatiksel anlaml kabul edildi (IBM SPSS Statistics for Windows, Version 21.0.; Armonk, NY, IBM Corp.).

\section{Bulgular}

Olguların 35'i kadın 39'u erkek olup ortalama yaş organik patolojiler için $34.17 \pm 8.93$ iken fonksiyonel disfoniler için $31.86 \pm 15.25$ olarak tespit edildi. Çalışmamıza dahil edilen organik ses patolojileri 23 kissing nodül, 7 unilateral nodül, 6 vokal kord polibi, 11 intrakordal kist, 6 reinke ödemi, 8 vokal kord paralizisi 
ve 5 sulkus vokalis olgusundan oluşmaktaydı. Cerrahi öncesi F0, vF0, Jitter, Shimmer, APQ (Amplitude Perturbation Coefficient), NHR (Noise Harmonic Ratio) ve VTI (voice Turbulance Index) değerleri (ortalama \pm SD) sirasiyla $229,62 \pm 61,52 ; 11,78 \pm 10,86$; $3,61 \pm 1,88 ; \quad 7,87 \pm 4,16 ; \quad 7,08 \pm 4,53 ; \quad 0,92 \pm 0,15 \quad$ ve $0,09 \pm 0,13$ olarak belirlenirken tedavi sonrası aynı değerler sırasıyla $218,74 \pm 67,92 ; 1,03 \pm 3,87 ; 1,02 \pm 0,79$; $3,96 \pm 2,45 ; 4,63 \pm 2,96 ; 0,23 \pm 0,21$ ve $11,83 \pm 0,21$ olarak belirlendi. Cerrahi öncesi ve sonrası karşılaştırıldığında VTI $(p=0.46)$ hariç tüm parametrelerde $(F 0, v F 0$, Jitter, Shimmer, APQ ve NHR) $(\mathrm{p}<0.05)$ istatiksel olarak önemli derecede fark bulunmuştur.

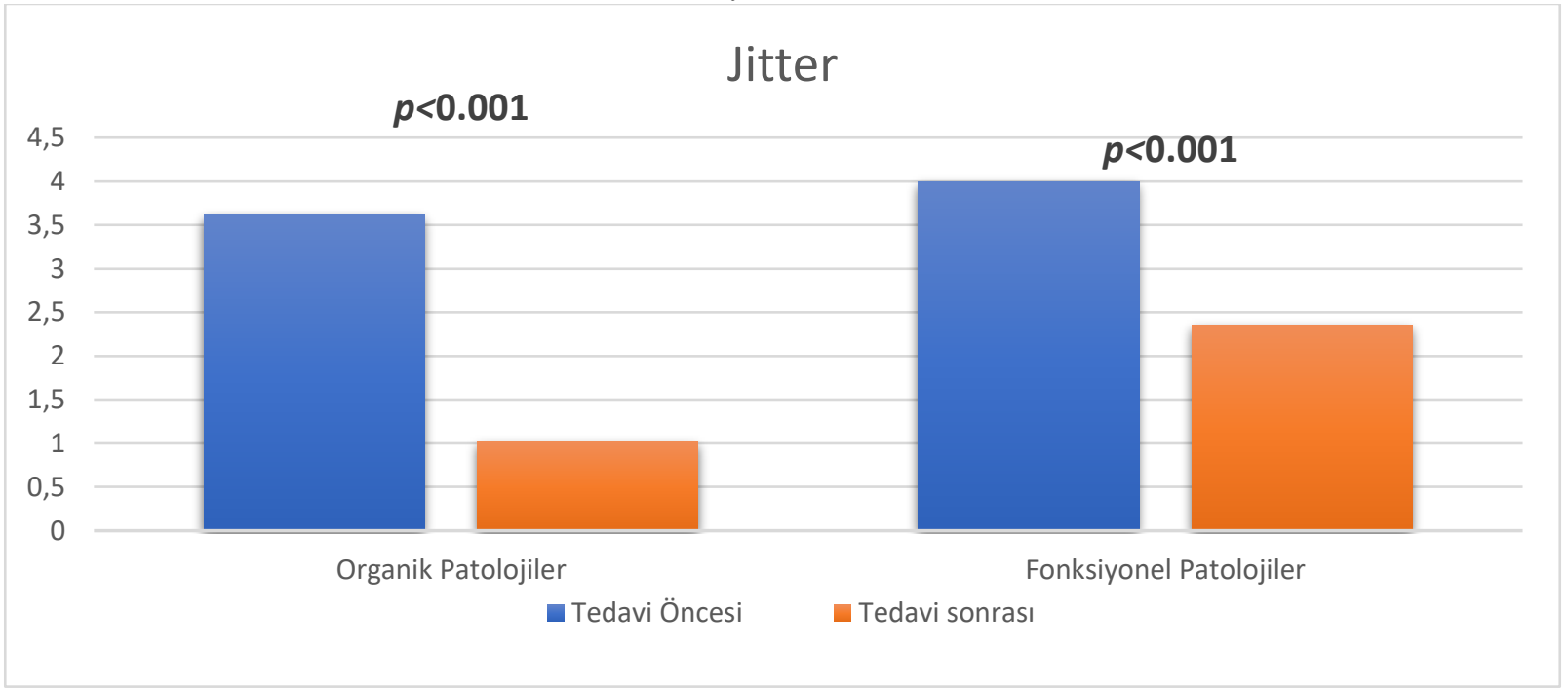

Şekil 1. Organik ve fonksiyonel ses patolojilerinde tedavi öncesi ve sonrası jitter değerlerini gösteren grafik.

Çalışmamıza dahil edilen fonksiyonel ses patolojileri ise 4 Spazmotik disfonin, 4 kas gerilim disfonisi, 2 mutasyonel falsetto ve 3 presbilarenks olgusundan oluşmaktaydı. Ses terapisi öncesi F0, vF0, Jitter, Shimmer, APQ, NHR ve VTI değerleri (ortalama \pm SD) sirasiyla $217,66 \pm 70,53 ; \quad 12,23 \pm 11,40 ; \quad 3,99 \pm 2,06$; $9,16 \pm 5,46 ; \quad 8,07 \pm 5,46 ; \quad 1,94 \pm 1,13 \quad$ ve $\quad 0,09 \pm 0,13$ belirlenirken tedavi sonrası aynı değerler sirasıyla $218,74 \pm 67,92 ; \quad 1,03 \pm 3,87 ; \quad 2,35 \pm 1,66 ; \quad 6,05 \pm 4,47$; $4,63 \pm 2,96 ; 0,24 \pm 0,09$ ve $0,06 \pm 0,03$ olarak belirlendi. Ses terapisi öncesi ve sonrası karşılaştırıldığında vF0, Jitter, Shimmer ve NHR parametrelerinde istatiksel olarak anlamlı değişiklik $(\mathrm{p}<0,05)$ tespit edilirken F0 $(p=0,09)$, APQ $(p=0,06)$ ve VTI $(p=0,13)$ parametrelerinde istatiksel olarak anlamlı fark bulunmamıştır. Özellikle disfoni ciddiyetini belirleyen jitter, shimmer ve NHR değerlerinin etiolojiye göre tedavi öncesi ve sonrası karşılaştırmalarına ait grafikler sırasıyla Şekil 1, Şekil 2 ve Şekil 3' te gösterilmiştir.

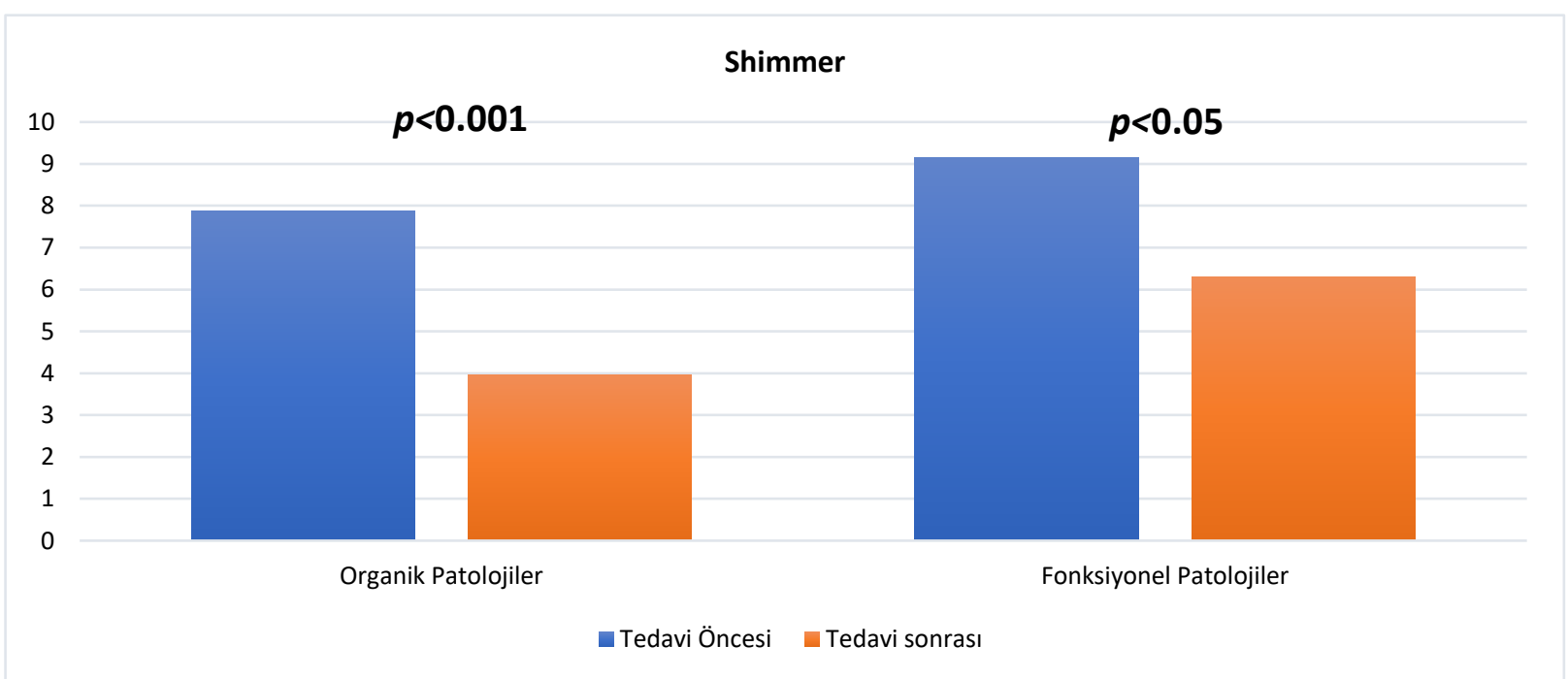

Şekil 2. Organik ve fonksiyonel ses patolojilerinde tedavi öncesi ve sonrası shimmer değerlerini gösteren grafik. 


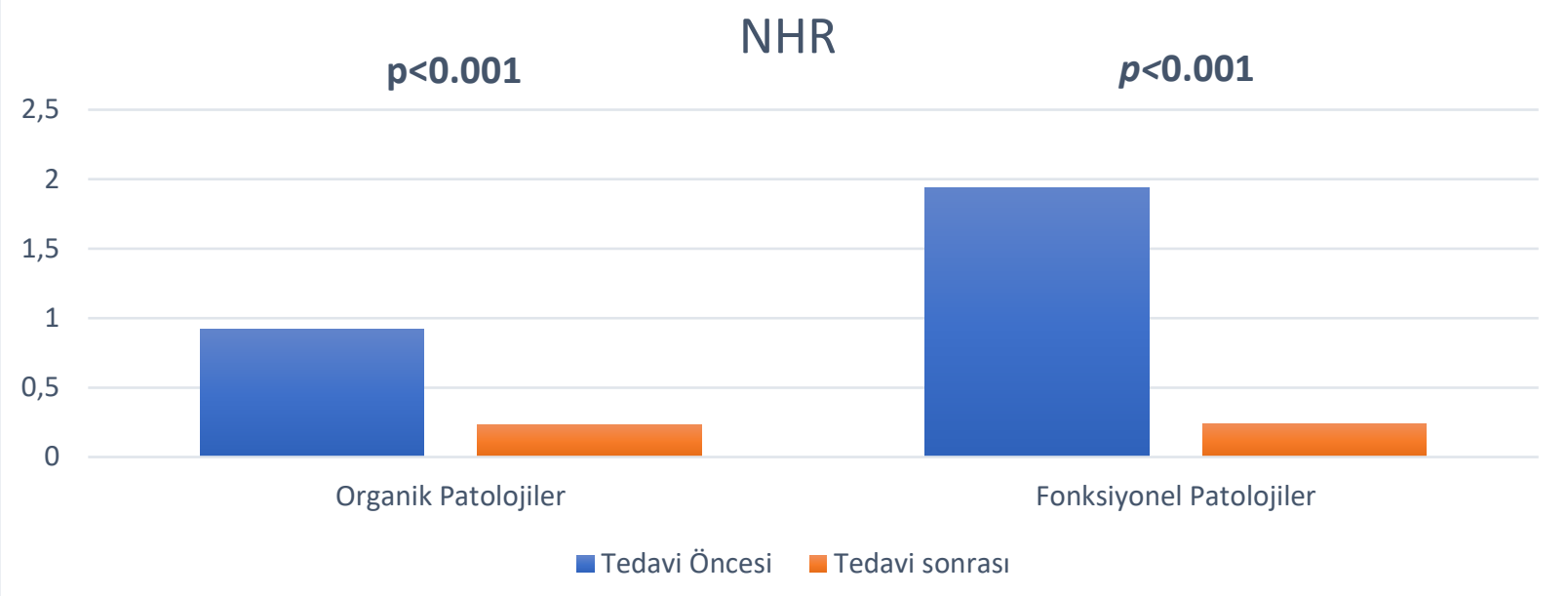

Şekil 3. Organik ve fonksiyonel ses patolojilerinde tedavi öncesi ve sonrası NHR değerlerini gösteren grafik.

\section{Tartışma}

Organik nedenli benign vokal kord lezyonlarının hepsinde olmasa da polip, nodül ve kist gibi s1k rastlananlarda ST veya FC primer tedavi olarak uygulanabilmektedir. Hatta ST'nin vokal kord nodülü tedavisinde ilk seçenek olması konusunda yaygın bir kanı oluşmuştur. Ancak polip başta olmak üzere diğer benign vokal kord lezyonlarında standart bir tedavi yöntemi henüz belirlenememiştir. Amerikan baş ve boyun cerrahisi derneği (AAO-HNS) üyeleri arasında yapılan anket çalışmasında vokal kord nodül tedavisinde \%91 ilk seçenek olarak FC'yi tercih ederken bu oran vokal kord polibi için \%22-30 olarak bildirilmiştir [8,9]. Ek olarak vokal kord poliplerinde cerrahiyi ilk seçenek olarak öneren birçok çalışma vardır [10,11]. Dolayısıyla organik nedenli vokal kord patolojileri dikkate alındığında ST ve FC önceliği, sıralaması ve etkinliği konusunda tartışmanın halen devam ettiği anlaşılmaktadır. Literatüre bakıldığında her iki tedavi yöntemini karşılaştıran çalışmalar daha çok spesifik ses lezyonlarına yöneliktir. Örneğin Vashani ve ark. reflü ilişkili ses hastalıklarında medikal tedavi (omeprazol) ve ST’nin etkinliğini karşılaştırmış ve ST'yi görece üstün olarak bildirmişlerdir [12]. Aksine Agarval ve ark. poliplerde FC ve ST'yi karşılaştırdıkları çalışmalarında FC'yi daha üstün bulmuşlardır (7].

Ses terapisi, vokal eğitim ve vokal hijyenin benign vokal kord lezyonlarındaki etkinliğini değerlendiren çalışmalara bakıldığında sonuçların çelişkili olduğu görülmektedir. Ayrıca, benign vokal kord lezyonlarına bağlı disfonik hastaları inceleyen çalıșmalarda bazı metodolojik problemler olduğu da gözükmektedir: (i) Organik nedenli disfonilerde ST'nin etkinliğini değerlendiren çalışmaların sayısı fonksiyonel disfonilerde ST'nin etkinliğini değerlendiren çalışmalardan çok daha azdır, (ii) Çalışmaların hemen hepsinde kontrol gurubu yoktur, (iii) İstatiksel olarak yeterli sayıda örneklem oluşturulamamıştır, (iv) Değerlendirme için sıklıkla sübjektif yöntemler kullanılmıştır. Ek olarak, bir ses terapisi seansında hastalara vokal hijyenin nasıl korunacağı öğretilmekte ve çeşitli vokal eğitim teknikleriyle fonatuar görevleri gerçekleştirmesi istenmektedir. $\mathrm{Bu}$ nedenle vokal kaliteyi gerçekten hangi faktörlerin arttırdığını ortaya koymak bu nedenle zor olmaktadır. Dolayısıyla vokal eğitim tekniği, vokal hijyen eğitimi ya da farklı vokal eğitim tekniklerinin etkinliğini ayrı ayrı inceleyen daha fazla sayıda çalışmaya ihtiyaç vardır. Ayrıca her bir vokal eğitim tekniğinin faydalı etkilerinin arkasındaki mekanizmaların aydınlatılması gerekir. Ayrıca histolojik olarak polip içerisinde henüz prolifere olmamış kılcal damarlar ST ile hasar görebilir. Bu nedenle ST seansı sonrası anlık ortaya çıkan değişiklikleri endoskopik olarak mutlak tespit etmek gerekir.

Bizim çalışmamızda disfoni ciddiyetini esas yansıtan parametreler (Jitter, shimmer, NHR) açısından organik lezyonu olan ve olmayan gurupta istatiksel olarak anlamlı derecede düzelme olduğu görülmüştür (Şekil 1,2,3). Ancak temel frekans (F0), temel frekans varyasyonu (vF0) ve genlik bozulma oranı (APQ) değerleri fonksiyonel ses hastalıklarında tedavi sonrası anlamlı derecede değişmezken organik patolojilerde anlamlı derecede düzelmiştir. Ses türbülans endeksinde (VTI) ise her iki gurupta da anlamlı derecede düzelme görülmemiştir. Çalışmamızın zayıf yönü benign ses hastalıklarının tek bir gurup olarak incelenmesidir. Farklı lezyonlarda FC ve ST'ye yanitlar farklı olabilecektir. Ancak çalışmamız dikkate alındığında FC 'nin bazı parametrelerde ST ile kıyaslandığında daha üstün olduğu söylenebilir. Çalışmamızın güçlü yanı ise objektif ses analizi yapılmış olmasıdır.

Organik lezyonlar tek başlarına değerlendirildiğinde poliplerde sadece ST ile tatminkar küçülme sağlandığ Garret ve Francis tarafindan öne sürülmüştür [13]. Bu nedenle her polipte hemen FC uygulamak doğru olmayabilir. $\mathrm{Bu}$ çalışmaya göre bir süre ses terapisi uyguladıktan sonra düzelme olmaması durumunda FC'yi uygulamak daha makul gözükmektedir. Ancak ne yazık 
ki polip özelinde tedavi uygulanmayan kontrol gurubu içeren çalışma bilgimiz dahilinde yapılmamıştır. $\mathrm{Bu}$ nedenle Garret ve Francis'in ortaya koyduğu sonuçların; vokal hijyen eğitimine mi? ST'ye mi? yoksa sadece zamana mı? bağlı olduğu konusu aydınlanmamıştır. Öte yandan benign vokal kord lezyonlarında doğrudan ST endikasyonunu destekleyen kanıt düzeyi yüksek çalışma yoktur.

Vokal kord kistlerinin ise salt ST ile ortadan kaldırılmasının oldukça güç olduğu bilinmektedir. Bu görüş, çoğu vokal kistin keratin ya da mukus birikmesi sonucu progresif olarak büyüdüğü bilgisi ile desteklenmektedir. Literatür dikkate alındığında vokal kord nodüllerinde ST etkinliğini gösteren çalışmaların polibi konu alan çalışmalardan daha az olduğu ve büyük kısmının zayıf metodolojiye sahip olduğu görülmektedir. Şöyle ki hiçbir çalışmada kontrol gurubu kullanılmadığı ve istatiksel olarak yeterli örnekleme sahip olmadıkları anlaşılmaktadır. Tüm bu bilgilere rağmen Sulica ve ark., benign vokal kord lezyonlarının tedavisini konu alan çalışmalarında, laringolojistlerin büyük çoğunluğunun (\%91) vokal kord nodülü tedavisinde öncelikli olarak ST önerdiklerini tespit etmişlerdir [14]. Ancak mevcut literatür dikkate alındığında yeterli kanıt içermeyen bu eğilim, cerrahi sonrası vokal kord nodüllerinin yüksek rekürrens oranına sahip olması nedenli bir tercih gibi gözükmektedir $[15,16]$. Wang ve ark. ise vokal kord nodüllerinde steroid enjeksiyonunun ST'den daha etkili olduğunu göstermişlerdir [17]. Gelecekte lokal steroid enjeksiyonu ve ST kombinasyonunun etkinliği ile ilgili çalışma yapılması tedavi konusundaki belirsizliklere katkıda bulunabilir.

Yukarıda vurgulandığı üzere vokal polip, nodül ve kist gibi vokal kord benign kitleleri ses kısıklığına yol açan oldukça sık rastlanan patolojilerdir. Vokal kord nodülleri sıklıkla sesini profesyonel kullanan kişilerde görülür ve bu hastalar neredeyse her yıl bu şikayetle ilgili tedavi görmek durumunda kalır [18]. Türkiye'de de benign vokal kord lezyonları yaygın olup bu olguların büyük kısmı disfoni şikayeti ile 1 . veya 2 . basamak sağlık kuruluşundan sağlık hizmeti almaktadır. Oysa bu seviyedeki merkezlerde ne vokal kaliteyi doğru değerlendirecek ses terapisti ne de objektif ses analizi yapabilecek teknik ekipman bulunmaktadır. Bu hastalar ancak ilk tedavide başarısızlık sonrası 3. Basamak sağlık kuruluşlarına yönlendirilmektedirler. Bu nedenle mevcut tedavilerin etkinliğini belirlemek ve kontrol gurubu oluşturmak güçleşmektedir.

Benign ses hastalıklarında ST ve FC dışında da bir takım tedavi yöntemleri tanımlanmıştır; i) spasmodik disfonibotoks, ii) vokal kord paralizisi-tiroplasti, botoks, iii) kas gerilim disfonisi- fizyoterapi. $\mathrm{Bu}$ nedenle sadece bu çalışmaya dayanarak ST ve FC etkinliğini değerlendirmenin gücü sınırlıdır. Ancak en azından cerrahinin akustik parametrelerde çok daha dramatik değişiklik yaptığını söylemek yanlış olmayacaktır.

\section{Sonuç}

Çalışmamız verileri dikkate alındığında ST'nin temel parametrelerde FC'ye yakın etkinlik sağladığı ancak bazı minör parametrelerde geride kaldığı tespit edilmiştir. Çalışmamızın zayıf yönü benign ses hastalıklarının tek bir gurup olarak incelenmesidir. Farklı lezyonlarda FC ve ST'ye yanıtlar farklı olabilecektir. Ancak çalışmamıza göre FC 'nin bazı parametrelerde ST ile kıyaslandığında daha üstün olduğu söylenebilir. Çalışmamızın güçlü yanı ise objektif ses analizi yapılmış olmasıdır.

\section{Referanslar}

1.Naunheim, MR, Carroll, TL, Benign vocal fold lesions: update on nomenclature, cause, diagnosis, and treatment, Current Opinion Otolaryngology Head Neck Surgery, 2017, 25(6), 453-458.

2.Hoffman, HT, Bock, JM, Karnell, LH, Ahlrichs-Hanson, J, Microendoscopy of Reinke's space, Annals of Otology Rhinology Laryngology, 2008, 117(7), 510-516.

3. Malik, P, Yadav, SPS, Sen, R, et al, The Clinicopathological Study of Benign Lesions of Vocal Cords, Indian Journal of Otolaryngology Head Neck Surgery, 2019, 71(Suppl 1), 212-220.

4.White A, Management of benign vocal fold lesions: current perspectives on the role for voice therapy, Current Opinion in Otolaryngology Head Neck Surgery, 2019, 27(3), 185-190.

5.Song, TE, Jiang, N, Transgender Phonosurgery: A Systematic Review and Meta-analysis, Otolaryngology Head Neck Surgery. 2017,156(5),803-808, doi:10.1177/0194599817697050.

6. Ropero Rendón, MDM, Ermakova, T, Freymann, ML, Ruschin, A, Nawka, T, Caffier, PP, Efficacy of Phonosurgery, Logopedic Voice Treatment and Vocal Pedagogy in Common Voice Problems of Singers, Advances Therapy, 2018,35(7),1069-1086.

7. Agarwal, J, Wong, A, Karle, W, Naunheim, M, Mori, M, Courey, M, Comparing short-term outcomes of surgery and voice therapy for patients with vocal fold polyps, Laryngoscope, 2019, 129(5), $1067-$ 1070.

8. Cohen, SM, Garrett, CG, Utility of voice therapy in the management of vocal fold polyps and cysts, Otolaryngology Head Neck Surgery, 2007, 136, 742-746.

9. Sulica, L, Behrman, A, Management of benign vocal fold lesions: a survey of current opinion and practice, Annals of Otology Rhinology Laryngology, 2003, 112, 827-833.

10. Jeong, WJ, Lee, SJ, Lee, WY, Chang, H, Ahn, SH, Conservative management for vocal fold polyps, JAMA Otolaryngology Head Neck Surgery, 2014, 140, 448-452.

11. Tang, SS, Thibeault, SL, Timing of voice therapy: a primary investigation of voice outcomes for surgical benign vocal fold lesion patients, Jounal of Voice, 2017, 31,129 e121-129 e127.

12. Vashani, K, Murugesh, M, Hattiangadi, G et al, Effectiveness of voice therapy in reflux-related voice disorders, Dis Esophagus, 2010, 23(1), 27-32.

13. Garrett, CG, Francis, DO, Is surgery necessary for all vocal polyps? Laryngoscope, 2014, 124, 363-4.

14. Sulica, L, Behrman, A, Management of benign vocal fold lesions: asurvey of current opinion and practice, Annals of Otology Rhinology Laryngology, 2003, 112, 827-33.

15. Pedersen, M, McGlashan, J, Surgical versus non-surgical interventions for vocal cord nodules, Cochrane Database Systematic Review, 2001, CD001934.

16. Be'quignon, E, Bach, C, Fugain, C, Guillere', L, Blumen, M, Chabolle, $\mathrm{F}$ et al, Long-term results of surgical treatment of vocal fold nodules, Laryngoscope, 2013, 123, 1926-30.

17. Wang, CT, Lian, LJ, Lai, MS, Cheng, PW, Comparison of benign lesion regression following vocal fold steroid injection and vocal hygiene education, Laryngoscope, 2014, 124, 510-5.

18. Simberg, S, Laine, A, Sala, E, Ro"nnemaa AM, Prevalence of voice disorders among future teachers, Journal of Voice, 2000, 14, 231-6. 
http://edergi.cbu.edu.tr/ojs/index.php/cbusbed isimli yazarın CBU-SBED başlıklı eseri bu Creative Commons Alıntı-Gayriticari4.0 Uluslararası Lisansı ile lisanslanmıştır.

(ㄷ) $(1) \Theta$ 